\title{
COMBINED PHYSICAL AND NUMERICAL MODELLING TO INFORM OPTIMAL MARINA DESIGN
}

\author{
Vincenzo Albanese ${ }^{1}$, Keith Powell ${ }^{2}$ and Giovanni Cuomo ${ }^{3}$
}

\begin{abstract}
A new Marina, capable of hosting up to 1,000 boats, is being constructed along the southern Tyrrhenian Sea coast of Italy. The Marina is separated from the shore by a $80 \mathrm{~m}$ wide channel and access to the harbour will be via a bridge designed by Santiago Calatrava. Design improvements and refinements were identified through physical and numerical model studies. This paper shows the important role of numerical and physical models in the design process of a marina. For this project the physical model study has confirmed the effectiveness of the optimised design.
\end{abstract}

Keywords: marina, numerical modelling, physical modelling

\section{INTRODUCTION}

Marina d'Arechi S.p.A. is constructing a new Marina, approximately $6 \mathrm{~km}$ to the South East of Salerno, on the southern Tyrrhenian Sea coast of Italy (Fig. 1).

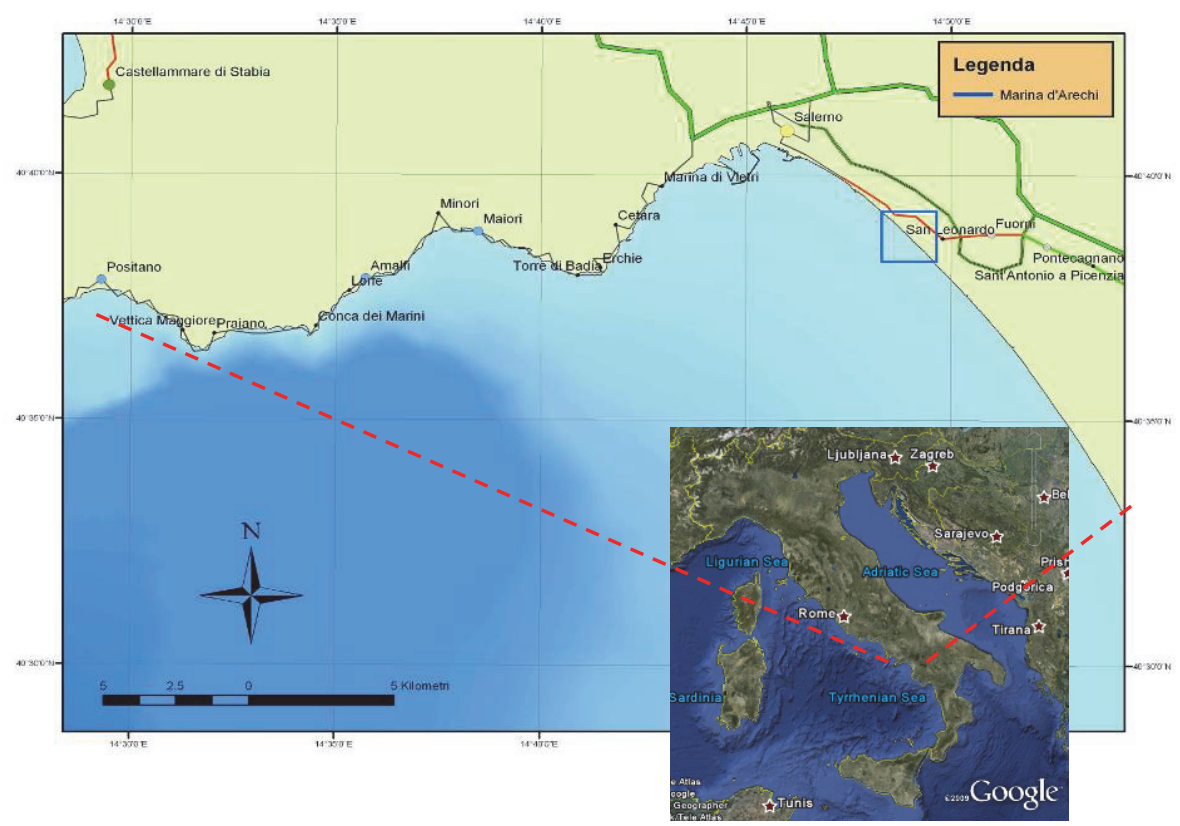

Figure 1. Marina d'Arechi location

Marina d'Arechi is a private marina and it is going to be one of the largest marinas in the Mediterranean. The owner and promoter of this marina is Gallozzi Group who set up in 2008 its associated company Marina d'Arechi Spa. The marina is capable of hosting up to 1,000 boats up to 60 $\mathrm{m}$ long with water depth from $3.5 \mathrm{~m}$ up to over $7 \mathrm{~m}$. The Marina is separated from the shore by a $80 \mathrm{~m}$ wide channel and access to the harbour will be via the bridge and the nautical club building designed by Santiago Calatrava (Fig. 2). The maritime structures were designed by Ing. Guglielmo Migliorino and the main breakwater (about $1.2 \mathrm{~km}$ long) is armoured using Accropode ${ }^{\mathrm{TM}}$ concrete units.

HR Wallingford was commissioned to undertake both numerical and physical model studies of the proposed development to evaluate its hydraulic performance in terms of:

- Breakwater wave overtopping and armour stability;

- Potential impacts of the proposed marina on the local sedimentary regime;

${ }^{1}$ Senior Engineer, HR Wallingford, Howbery Park, Wallingford, Oxfordshire OX10 8BA, United Kingdom,

v.albanese@hrwallingford.com, t: +44 (0) 1491822272 , f: +44 (0) 1491832233

2 Director, HR Wallingford Ltd, Howbery Park, Wallingford, Oxfordshire OX10 8BA, United Kingdom,

k.powell@hrwallingford.com, t: +44 (0) 1491 822232, f: +44 (0) 1491832233

3 Principal Engineer, HR Wallingford Ltd, Howbery Park, Wallingford, Oxfordshire OX10 8BA, United Kingdom, g.cuomo@hrwallingford.com, t: +44 (0) 1491 822414, f: +44 (0) 1491832233 
- Wave agitation;

- Flushing characteristics and water quality.

Numerical models and desk studies were initially performed to optimise the original design (plan shape and cross sections) to ensure stability of the breakwaters, reduce harbour agitation, assess wave and tide induced currents and corresponding sediment fluxes and flushing capability. A physical model was then used to confirm the stability and overtopping of the main breakwater, assess harbour agitation and provide further insights into the complex circulation in and around the marina and the associated sediment transport regime, particularly at the entrances to the channel behind the marina.
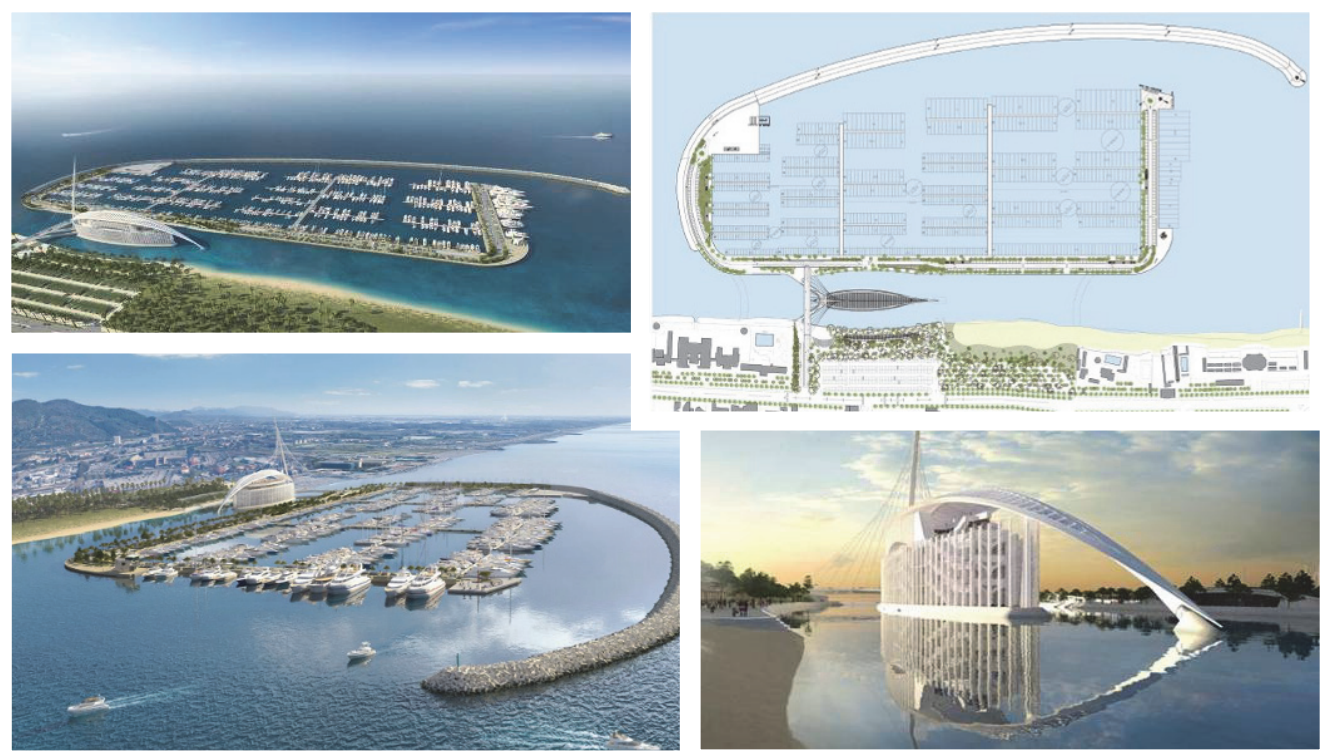

Figure 2. Marina d'Arechi layout

The coast in the area where the marina will be located is facing serious coastal erosion problems (Fig. 3). Marina d'Arechi is intended to be part of a wider waterfront development and coastal protection project for the gulf of Salerno. To the north of the marina the frontage will be protected by submerged breakwaters with beach renourishment and to the south of the marina 6 rock groynes will be installed (Fig. 3).
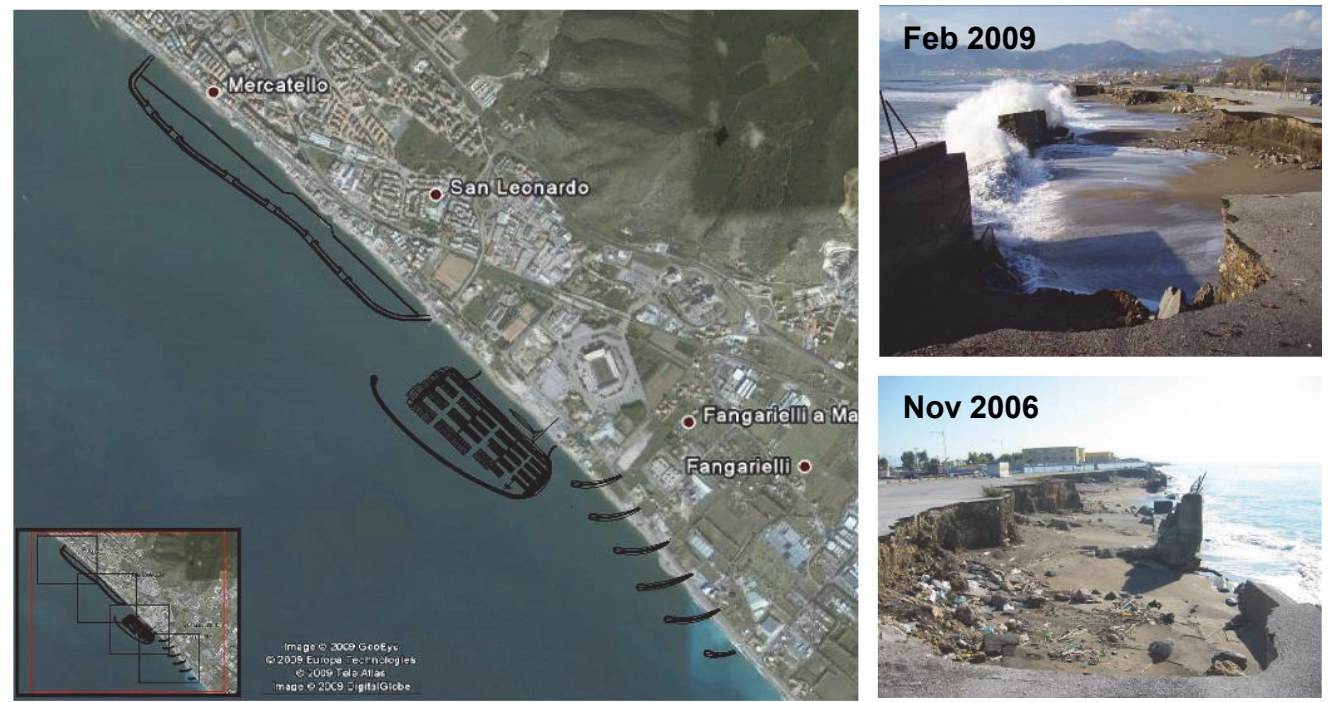

Figure 3. Gulf of Salerno coastal protection scheme and example of coastal erosion 


\section{NUMERICAL MODEL STUDIES}

Different numerical models were used to evaluate:

- Offshore and nearshore wave conditions;

- Wave agitation at the marina entrance and berths;

- Potential sedimentation and erosion in the vicinity of the Marina;

- Flushing of the Marina and of the channel between the Marina and the coastline;

- Future long-term beach behaviour adjacent to the Marina.

\section{Offshore and nearshore wave conditions}

In examining the effects of coastal structures on the shoreline, and their hydraulic performance, with numerical and physical models it is first necessary to establish appropriate forcing conditions with which to drive them. To this end it is important to determine a reliable representation of the wave climate experienced at the site; the greater the level of confidence in the representation of the wave climate, the greater the level of confidence in the modelled sediment movement. From such a climate, it is then possible to determine extreme wave conditions that might be experienced at the site, and also to extract from this climate time-series of wave conditions relating to particular storm events.

It is general practice to utilise the longest possible reliable data set of forcing conditions when investigating long-term changes and extreme events. In the absence of long series of measured wave data at the site of interest (the most usual case), it is now routine to use results from numerical wavehindcasting models to provide information on wave conditions. To enable predictions of wave conditions near the coast, it is first necessary to specify realistic (or calibrated) wave conditions offshore of the region being modelled. These offshore wave conditions further need to be represented in the form of directional wave spectra for subsequent input to the wave transformation hindcasting model used to derive the nearshore conditions.

The basic principle behind the wave modelling procedure adopted for this study is to build a wave hindcasting model which utilises long time-series of wind data to hindcast corresponding wave conditions. The UK Meteorological Office runs a European Wave Model which is able to provide 20 years (October 1986 to December 2006) of wind and wave conditions at three-hourly intervals, and the use of this model as a source of wind data allows for a better spatial coverage than from an anemometer station. The hindcast wave conditions are then calibrated against observed wave records from the Ponza buoy - part of the Italian national network of wave buoys (RON). Calibration of hindcasting wave models can take several forms; the most common being to apply "mark-up" factors to discrete bands of wind-strength such that observed percentage exceedence levels are reproduced by the model. This procedure was applied for this study (Fig. 4).

Ordinarily, such a calibration alone would be sufficient to allow the application of the model with some degree of confidence. Confidence in model predictions can be further increased by comparing the calibrated model against a second modelled dataset elsewhere in the model domain. In this study the calibrated model behaviour was tested by comparing hindcast data in deep water offshore of the Marina d'Arechi site against deep water wave climate obtained from the Met Office European Wave Model. This has increased the confidence in model behaviour.

Once calibrated and validated, the model was then used to hindcast an entire nearshore wave climate in shallow water in the vicinity of Marina d'Arechi. The hindcasts were carried out using the same wind mark-up factors determined during the calibration phase, so confidence in the predictions is high. The nearshore wave climate time-series was then analysed to provide extreme conditions locally to the structures. HR Wallingford's WAVEMaT model was used to derive the offshore and nearshore wave conditions. 


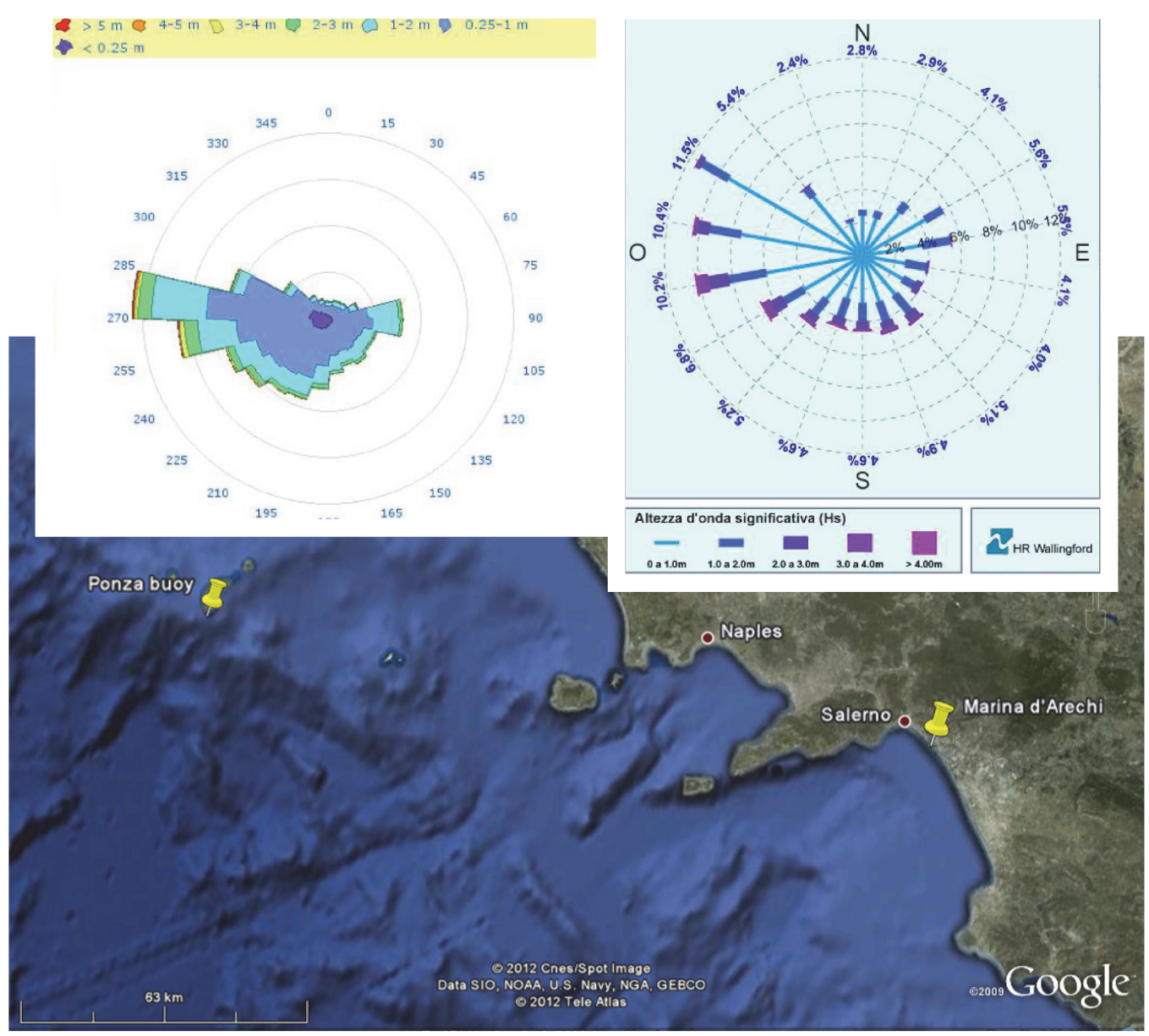

Figure 4. Wave roses from RON Ponza buoy (left) and calibrated WAVEMaT hindcast (right) at the same location

\section{Wave disturbance at the marina berths}

An assessment of the likely levels of wave agitation within the marina itself was undertaken to improve the functionality of the marina basin. Three return periods were considered: once per summer (defined as the three months of June, July and August), once per year, and once per fifty years. Three offshore wave directions were considered: $210^{\circ} \mathrm{N}$ and $240^{\circ} \mathrm{N}$ as these are the worst cases for breakwater stability, and $290^{\circ} \mathrm{N}$ as the main breakwater offers little protection against locally generated waves from this direction. Two groups of berths were considered: those within the main area of the marina, sheltered by both breakwaters, and the 'summer berths' on the seaward side of the shorter north-western breakwater. HR Wallingford's ARTEMIS model was chosen for its capability to represent multiple reflecting surfaces and diffraction around the breakwater head, in addition to simulation of a directional spectrum, refraction, shoaling and energy dissipation.

Initial wave model runs indicated that wave conditions within the main basin of the marina are acceptable but that at the 'summer berths' would be too high during the once per summer conditions (Fig. 5). In order to provide comfortable mooring condition at the 'summer berths' it was recommended to extend the main breakwater by $80 \mathrm{~m}$ and slightly re-orientate its outer end. 

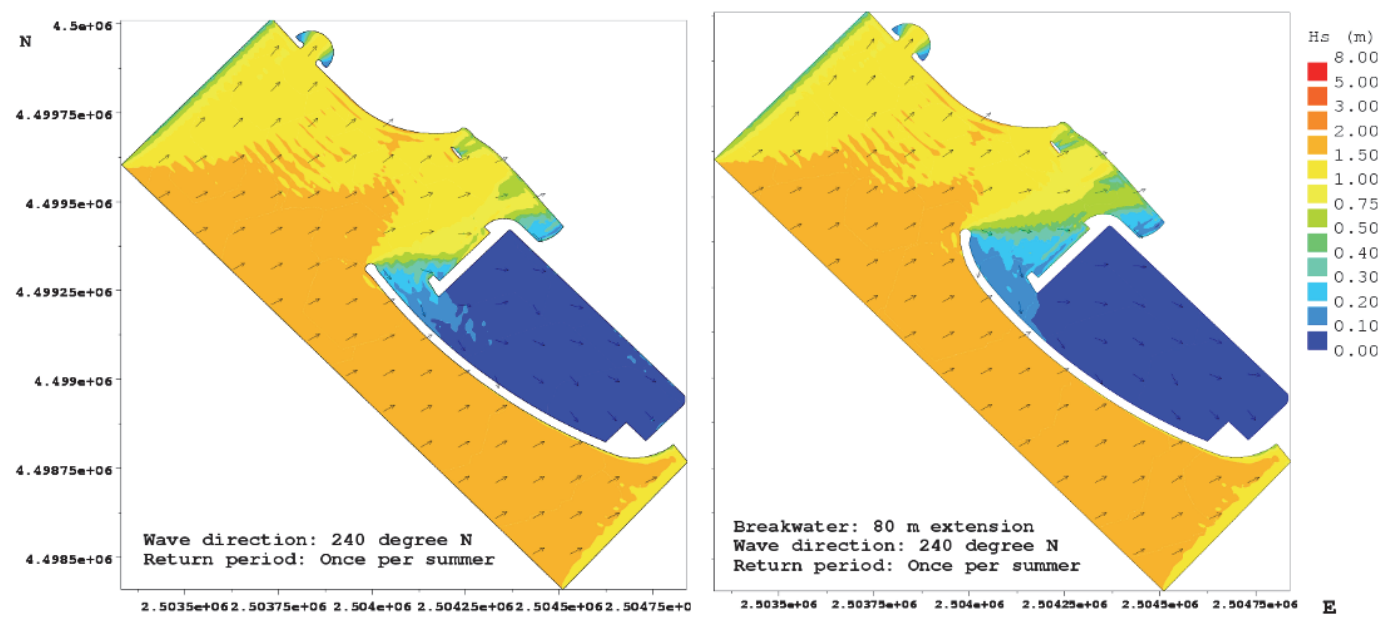

Figure 5. Wave model results: offshore direction $240^{\circ} \mathrm{N}$; once per summer (with and without $80 \mathrm{~m}$ extension)

\section{Potential sedimentation and erosion in the vicinity of the Marina}

The potential sand transport patterns along the coastline in the vicinity of the proposed Marina d'Arechi and resulting patterns of potential sedimentation and erosion were assessed, in particular along the length of the channel between the Marina and coastline. HR Wallingford's PISCES morphodynamic modelling system was used to simulate the developed test cases. PISCES consists of individual modules for waves, tidal and wave-driven currents, and sand transport. These modules are linked up to exchange information and work interactively. In the present study PISCES consisted of the second generation wave model TOMAWAC, the depth-averaged flow model TELEMAC2D (both developed by the National Hydraulics and Environment Laboratory of Electricite de France LHNEDF) and the depth-averaged sand transport model SANDFLOW (developed by HR Wallingford).

TOMAWAC computes the generation and propagation of waves in coastal waters for given wind, seabed and current conditions. It is particularly suited to the generation and transformation of waves over relatively large coastal areas. TELEMAC2D solves the 2D depth-integrated shallow water equations which are used to model flows in rivers, estuaries and seas. The model can simulate depth integrated tidal flows in estuaries and seas including the presence of drying banks. SANDFLOW uses the flows calculated by TELEMAC2D and wave orbital velocities calculated by the TOMAWAC wave model to determine the transport, deposition and erosion of non-cohesive (sandy) sediment and thereby identify areas of potential siltation and erosion.

The 'worst case' conditions assessed in order to give a representation of unfavourable conditions were those with a return period of one year. For this numerical modelling study it was estimated that a south-westerly direction would likely be most unfavourable for potential sedimentation in the channel between the Marina and the coastline. Relatively frequently occurring metocean conditions were also examined.

Initial model runs indicated that currents along the channel between the Marina and coastline are quite high and there is a risk of sedimentation at both channel entrances. Hence it was recommended to introduce sills at either end of the channel (Fig. 6). 


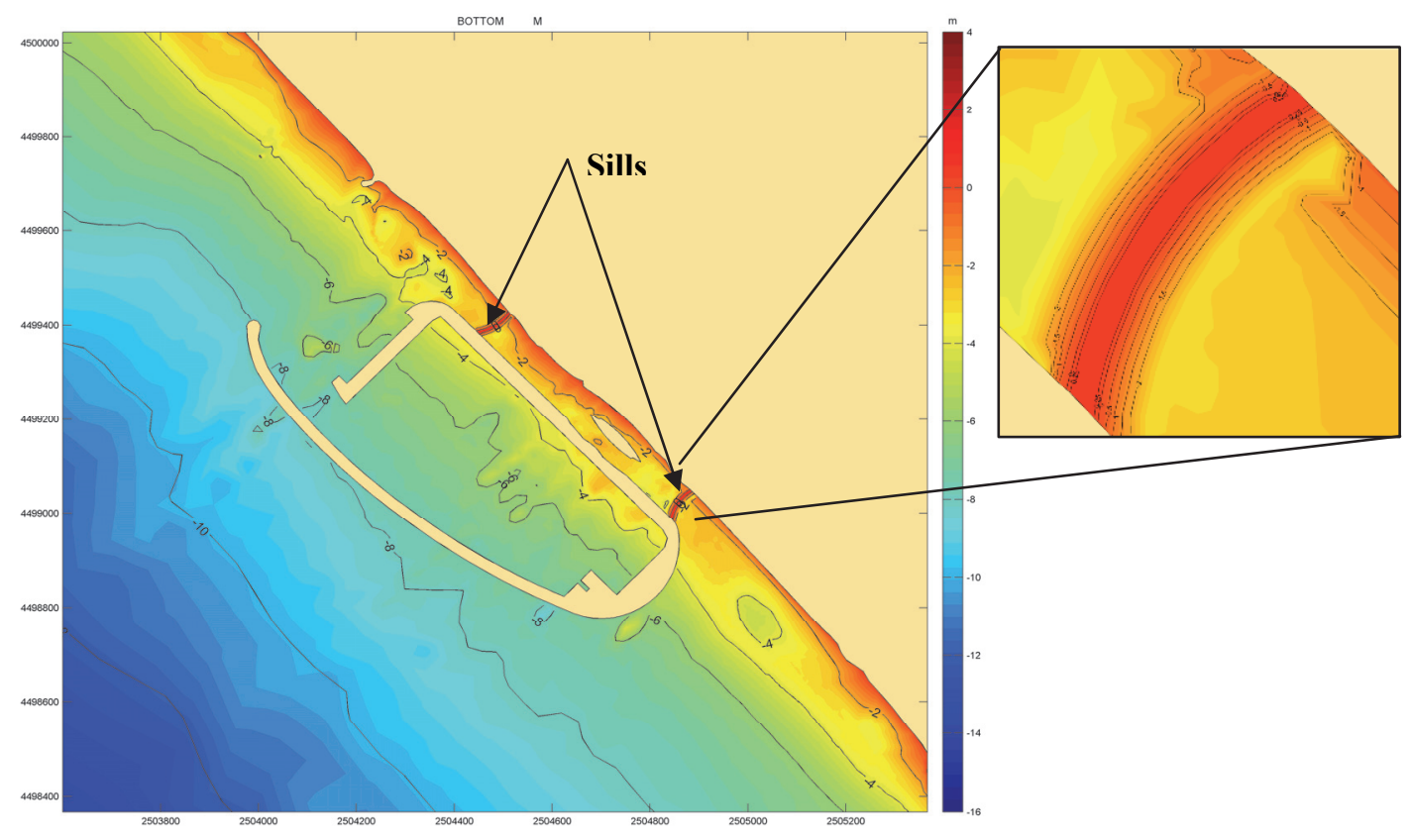

Figure 6. Sills located at either end of the channel

The potential sedimentation and erosion in the vicinity of the Marina was assessed considering two layouts with and without additional proposed development of the Salerno waterfront,(Fig, 7), and with the presence of the two sills located at either end of the channel. On the basis of the model results of sand transport, sedimentation and erosion the following conclusions were drawn:

- The highest sand transport is predicted in the areas of wave diffraction to the immediate north and south of the Marina, adjacent to the coastline. These predicted nearshore sand transport patterns indicate nearshore transport toward the sills;

- The imposed 'worst case' offshore wave conditions cause a generally northward littoral drift that is mainly confined between the shoreline and the $-4 \mathrm{~m}$ bed level. There is also the possibility that a small portion of the transported sediment can bypass the main breakwater. Tidal effects are relatively small;

- Immediately to the north of the Marina the sheltering causes an oppositely directed drift toward the south, i.e. toward the channel between the Marina and the adjacent coastline;

- The imposed moderate and more frequently occurring offshore wave conditions generate significantly less potential for sediment transport in the near-shore zone around the Marina structure;

- The additional development of the Salerno waterfront proposed on either side of the marina leads to a clear reduction in the potential longshore drift. There is however a potential for sand transport from the beaches between the groynes to the south of the Marina, directed toward the southern channel entrance. The southward directed drift toward the northern channel entrance is also reduced, however a risk of sedimentation remains;

- The main drift pattern is not affected by the presence of the channel sills, with sand transport toward both channel entrances being limited to the location of the sills.

Figure 7 shows the patterns of potential erosion and deposition over a period of one tidal cycle, with and without the presence of the Salerno waterfront development and considering the 'worst case' conditions. The results clearly show the effect of the proposed Salerno waterfront development on the potential sand transport. The area of potential sedimentation near the southern channel entrance is concentrated in the area in the vicinity of the sill. 


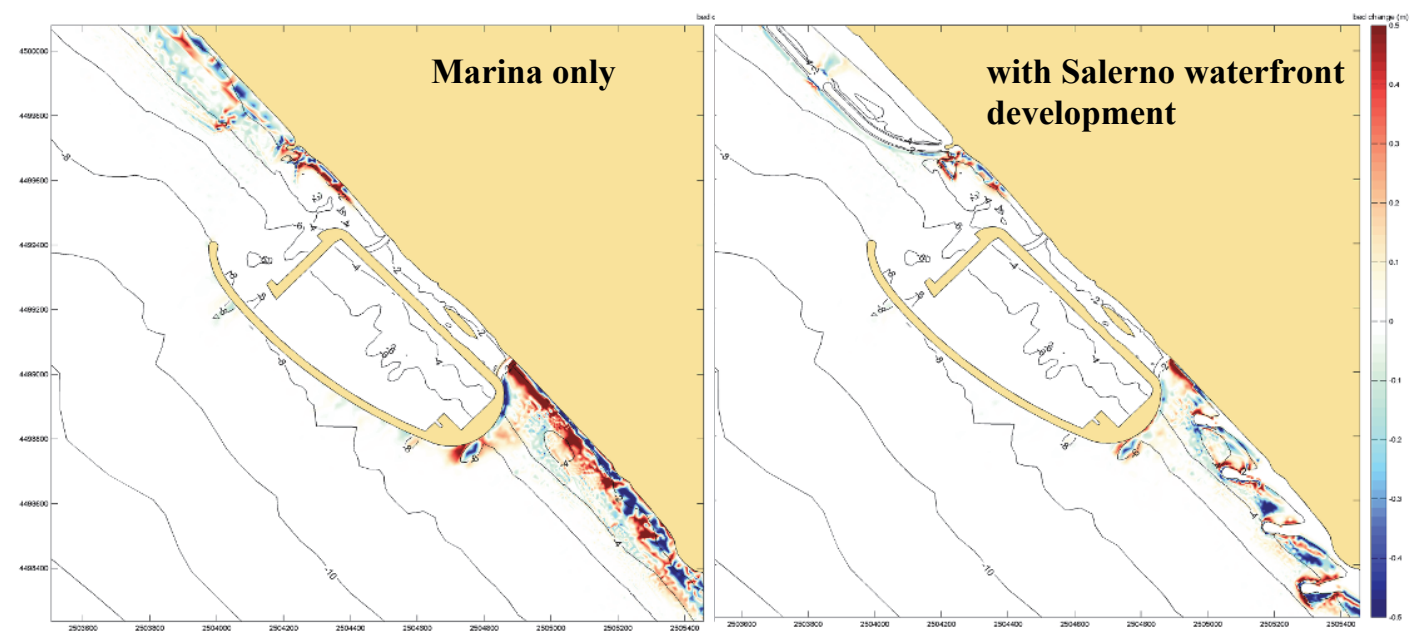

Figure 7. Pattern of potential erosion (blue) and deposition (red) - with and without the Salerno waterfront development

\section{Flushing of the Marina and of the channel between the Marina and the coastline}

The flushing of the water body in the proposed Marina d'Arechi and flushing of the channel between the Marina and the adjacent coastline was also assessed. The DELWAQ flushing model was used in this assessment. DELWAQ is a two-dimensional water quality model framework that solves the advection-diffusion equation for a wide range of model substances. DELWAQ used flow fields derived from previous hydrodynamic computations using TELEMAC2D.

In this study it was considered that calm conditions were likely to result in the lowest water exchange rates for the Marina and the channel. Therefore the 'worst case' conditions defined for the flushing study consisted of the design tidal condition without addition of wind- or wave-driven currents. Relatively frequently occurring metocean conditions were also assessed.

Flushing of the Marina and of the channel between the Marina and the adjacent coastline was investigated with and without the proposed Salerno waterfront development. The results of the flushing assessment of the Marina under the imposed conditions indicated for all cases that less than $37 \%$ of the initial tracer mass remains in the Marina after the simulated period of 10 days if a $1 \mathrm{~m}^{3} / \mathrm{s}$ clean water discharge is pumped in the southeast corner of the Marina. In this scenario the results are satisfactory when compared to the PIANC 2008 guidelines, which recommends that a maximum of $37 \%$ is acceptable.

The results of the flushing assessment of the channel between the Marina and the adjacent coastline under the imposed conditions indicate that the relative tracer mass drops below the PIANC 2008 guideline of " $37 \%$ after ten days" of the initial mass over a period of approximately 7.5 days with the inclusion of $0.1 \mathrm{~m}^{3} / \mathrm{s}$ clean water discharge at a location centred between the sills.

\section{Future long-term beach behaviour nearby the Marina}

The likely future long-term behaviour of the beaches nearby the Marina (ie how the shoreline might be expected to change in response to longshore gradients in littoral drift), was also investigated. The HR Wallingford's BEACHPLAN model was adopted for this assessment and following an historical review, appropriate data was selected for the set-up, calibration and validation of the sediment transport model.

The model, which covered approximately $3.5 \mathrm{~km}$ of coastline centred on the Marina, was driven by the 20 -year inshore wave climate. It was assumed that the wave climate of the last 20 years would have been representative of that of the next 20 years. The potential long-term behaviour of the beaches nearby the Marina was assessed considering two layouts with and without the proposed Salerno waterfront development, and the following conclusions were drawn:

- The Marina has a sheltering effect on the coastline behind it and a twin salient/tombolo is formed at either end of Marina which can often occur where long breakwaters are in place 'pulling' sediment into the sheltered area, mainly due to longshore gradients in wave height and diffraction processes (Fig. 8).

- With the proposed Salerno waterfront development layout in place, the nourished beach to the south of Marina d'Arechi, controlled by 6 groynes, exhibits occasional build-up of sediment 
against the structures updrift. The beaches, located in the groyne bays, remain fairly stable with some fluctuations depending upon the wave climate and tend to show that a reorientation of the shoreline from the design state will occur soon after construction.

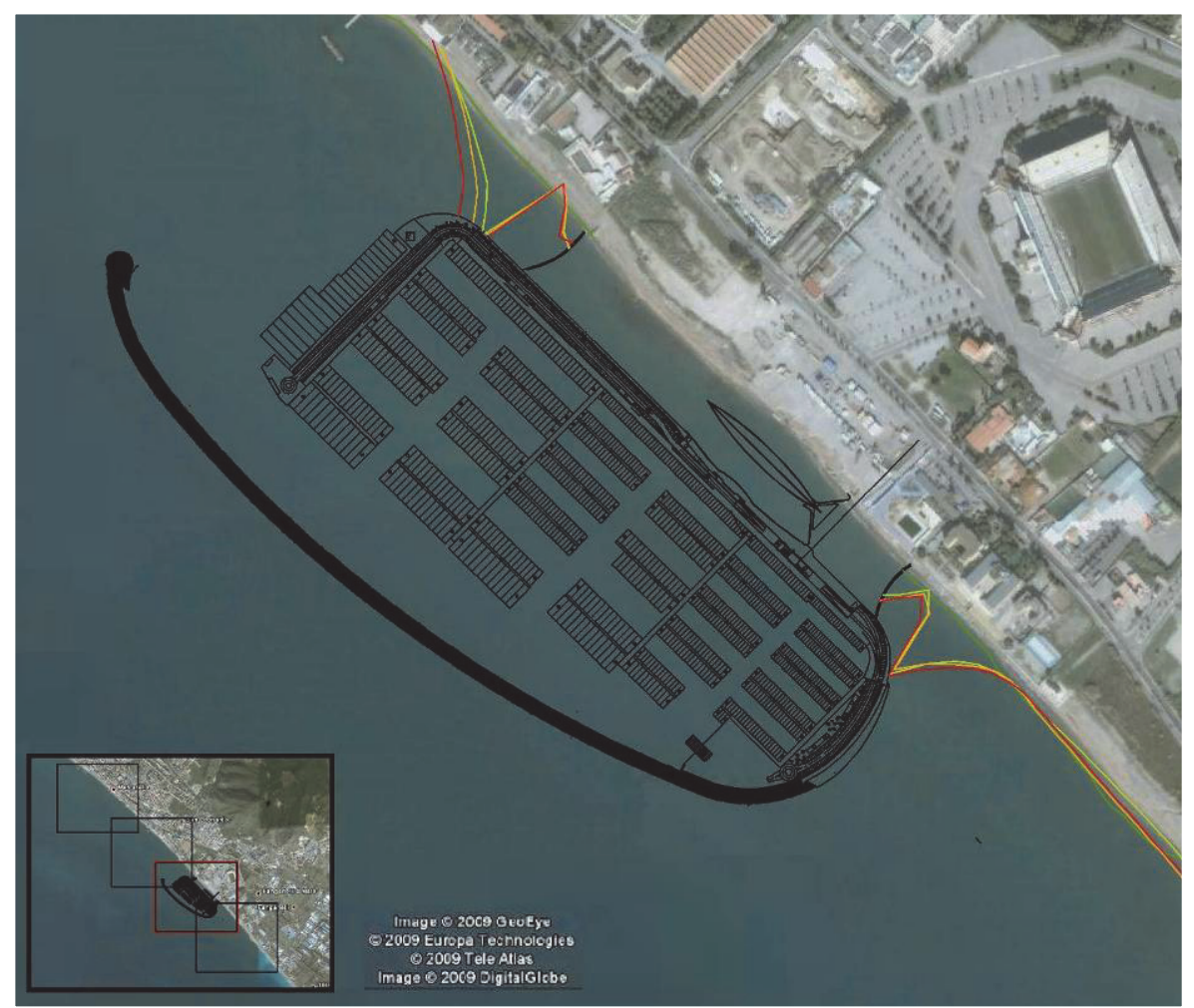

Figure 8. Shoreline evolution after 20 years (red line) - twin salient/tombolo formed at either end of Marina

\section{D PHYSICAL MODEL STUDY}

The initial design was optimised incorporating the refinements and recommendations identified by means of desk studies and numerical model studies. 3D physical model tests were then conducted to verify the hydraulic performances of the proposed design of the Marina with the following objectives:

- To confirm the stability of the primary armour layer, specifically for Accropode ${ }^{\mathrm{TM}}$ and rock armour.

- To investigate mean overtopping discharges at key location along the breakwater.

- To measure wave agitation at the harbour mouth as well as at berths.

- To measure wave-induced current velocity and direction at site specific locations within and around the marina.

\section{Model facilities and tests}

The model was tested in one of the six 3D wave basins in HR Wallingford's Froude Modelling Hall. The basin used is $38.5 \mathrm{~m}$ long by $30 \mathrm{~m}$ wide (model), and can operate with water depths of up to $0.8 \mathrm{~m}$. The layout of the model is shown in Figure 9 and the Marina was modelled to a scale of 1:60. Waves were produced by a $24 \mathrm{~m}$ long, multi-element absorbing wave generator driven by an electric motor system. Wave guides were used at either end of the generator to contain the waves within the modelled area and extended close enough to the modelled area to prevent energy loss by diffraction, but not so close as to allow a build up of reflected waves. The basin's walls were lined with gravel spending beaches to reduce unwanted reflections. The model was designed to generate waves from $210^{\circ} \mathrm{N}$ and $240^{\circ} \mathrm{N}$.

The wave generator produces either long-crested or short-crested random sea states. For this study, long crested waves were used throughout. The input signal to the wave generator is produced by a random wave synthesiser, which uses HR Wallingford's HRWavemaker software. HRWavemaker is capable of producing random sea states to any required spectral shape. For this study JONSWAP spectra with $\gamma=2.15$ were used. Model wave data was acquired and analysed by 
HRW's HRWaves software, which contains spectral and statistical analysis routines. Waves were measured using twin-wire resistance gauges, with a resolution of less than $0.1 \mathrm{~mm}$ at model scale.

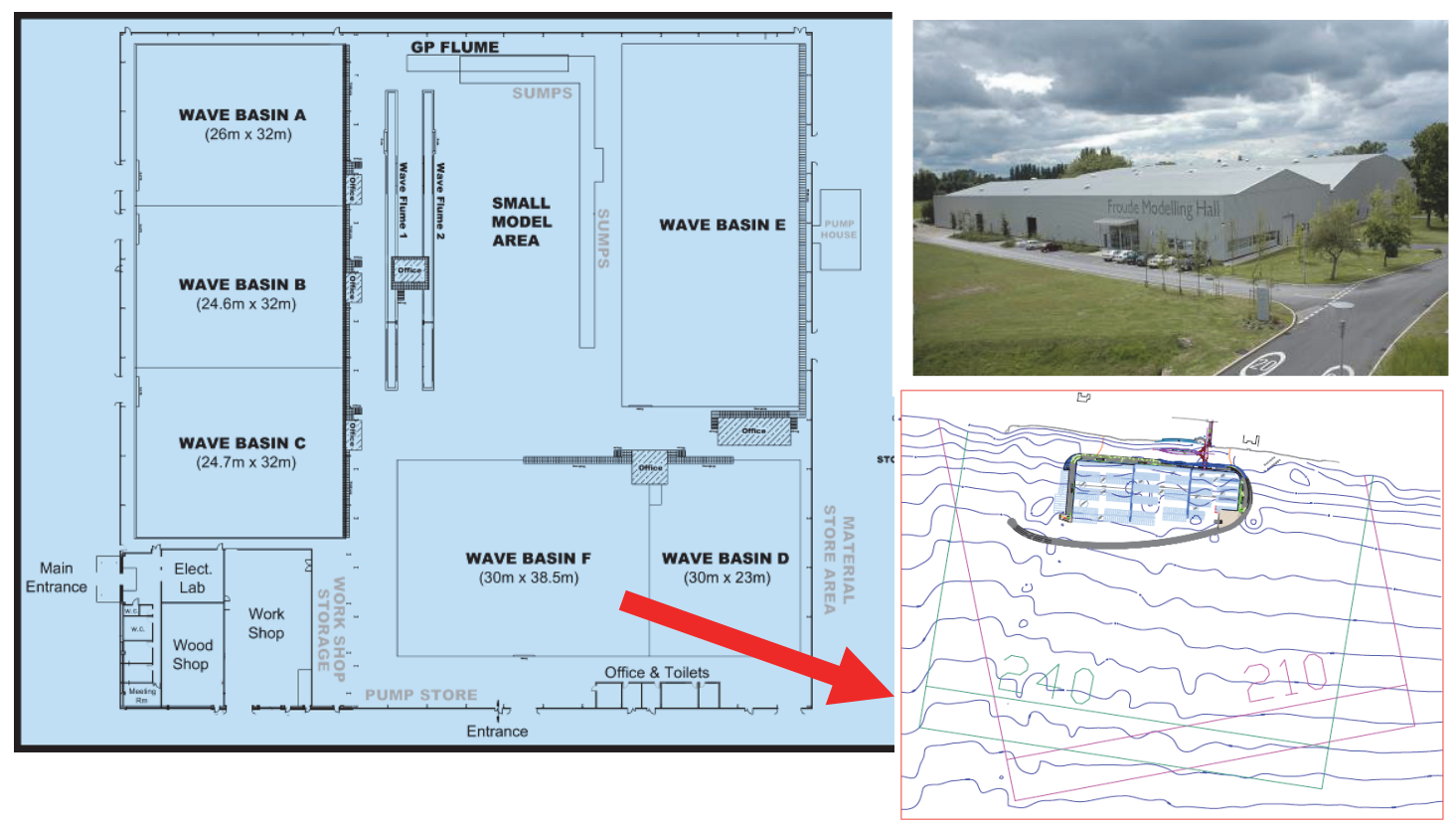

Figure 9. HR Wallingford's Froude Modelling Hall, model layout and paddle positions $\left(210^{\circ} \mathrm{N}\right.$ and $\left.240^{\circ} \mathrm{N}\right)$

The hydraulic performance of the Marina was investigated over a variety of sea states, including:

- $1: 1$ year condition;

- 1:10 year condition;

- 1:120 year condition;

- Overload condition.

The overload condition used wave height $20 \%$ higher than the design condition. The test results were compared with widely accepted guidelines for the performance of similar structures.

Calibration of the selected conditions was carried out before any of the structures were constructed in the model. The waves were calibrated on the $-8.5 \mathrm{~m}$ MSL contour for each of the two wave directions $210^{\circ} \mathrm{N}$ and $240^{\circ} \mathrm{N}$.

\section{Armour stability}

Each armour stability test was run for a duration of 6 hours (prototype), using a consistent procedure to ensure that the same wave sequences were used on each test. The length of the wave sequence (the time taken before the wave record begins to repeat) was considerably longer than the actual test length, thus ensuring that any particular group of waves only occurred once.

Two methods were used to assess the armour stability, as follows:

- Visual observations of armour stability were made throughout the test series. Notes were taken of areas and types of damage and the type of wave conditions.

- Armour stability was assessed using a more accurate overhead photographic technique. Photographs were taken from fixed camera positions covering the seaward and leeward sides of the structure before and after each test. Before the overhead photographs were taken, the basin was drained so that all of the structure was visible. Successive transparent prints were then compared to identify instances of armour displacement.

Before the beginning of each test series and at the end of each test, pictures of the structure were taken and relative displacement of each unit noted. Position of cameras used to assess the stability of the armour units are indicated in Figure 10. 


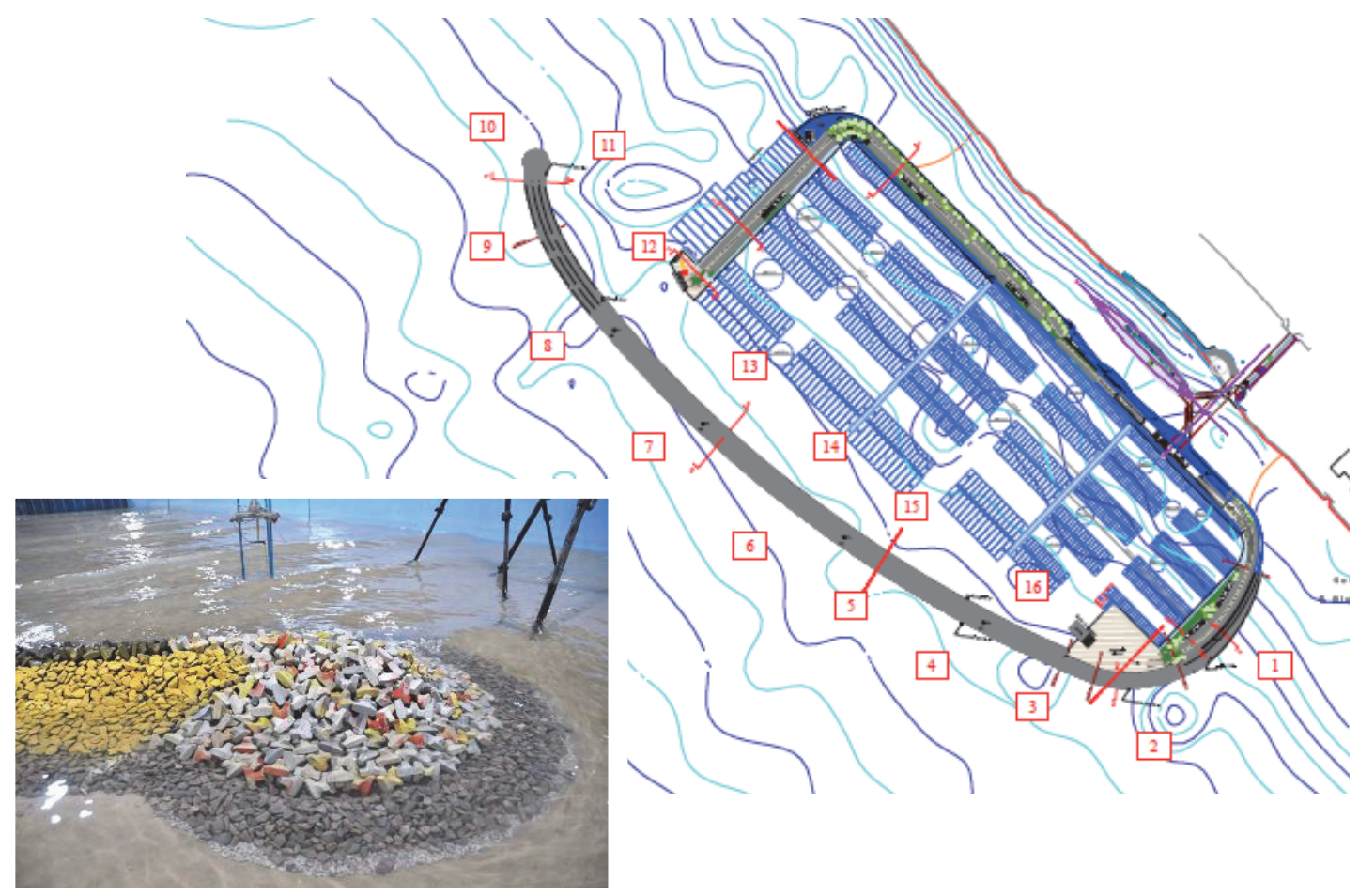

Figure 10. Position of cameras used to monitor armour stability for both $210^{\circ} \mathrm{N}$ and $240^{\circ} \mathrm{N}$ Test Series

No movement of the Accropode ${ }^{\mathrm{TM}}$ units was observed for any of the condition tested. In particular, there were no extractions and no units were seen to be rocking during the tests. The criteria for the assessment of damage to model Accropode ${ }^{\mathrm{TM}}$ units and rock armour following physical model tests. (CLI, 2011 and BSI 6349, 1991) were therefore met.

Settlement movements and displacements might be expected at the toe due to the high levels of turbulence generated in the troughs of the waves as they passed along the breakwater. There was some movement of the toe armour across many of the test parts but mostly with units rotating around their original position but not being dislocated. The toe remained stable throughout testing; the damage was minor and would not affect the performance of the breakwater for the conditions tested.

\section{Wave disturbance}

During testing of armour stability, wave agitation was also measured at selected locations including:

- the marina entrance

- the inner berths

- the summer berths.

Waves were monitored using a total of 32 wave probes at key location as indicated in Figure 11. 


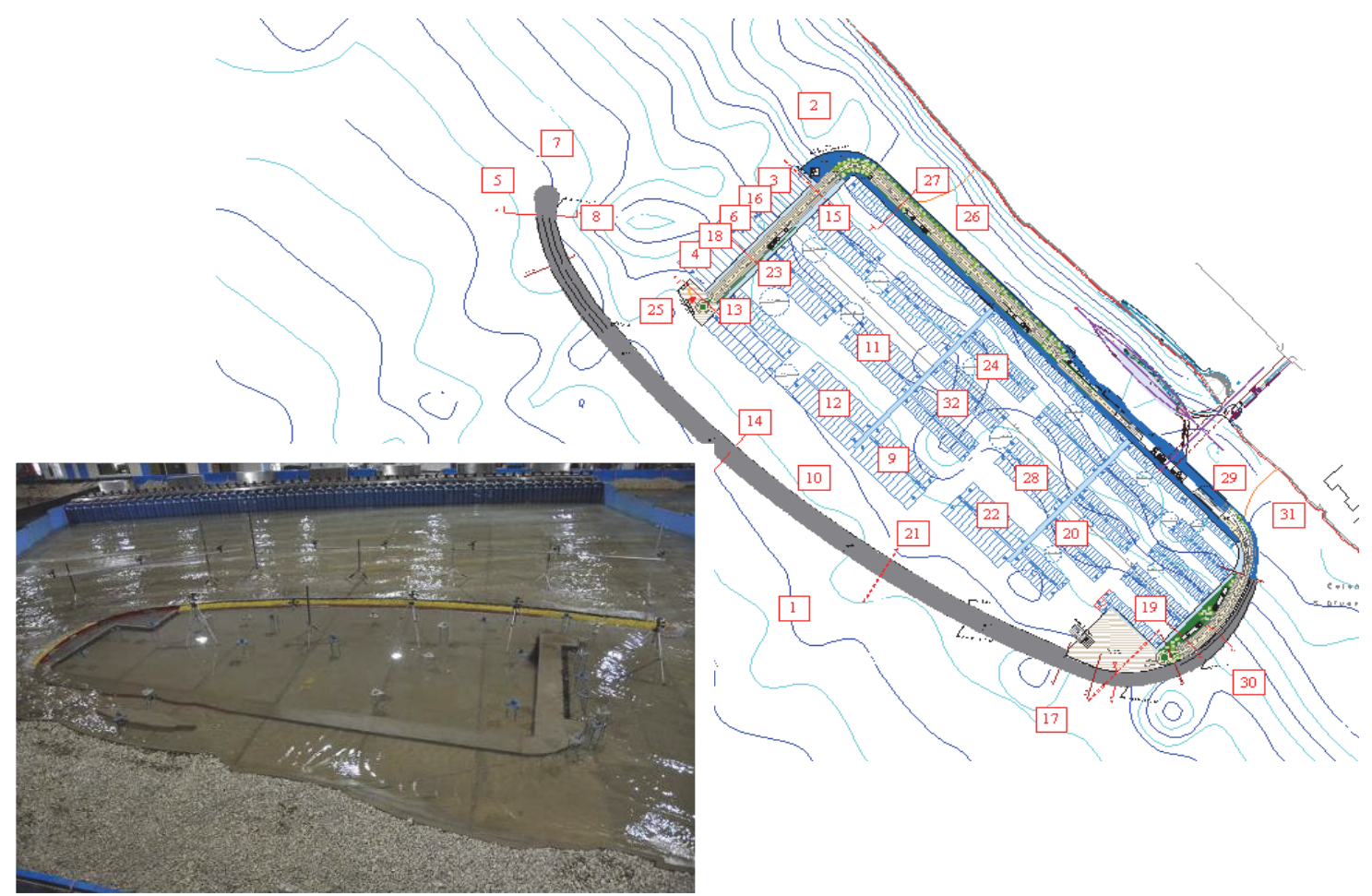

Figure 11. Locations of wave probes for both $210^{\circ} \mathrm{N}$ and $240^{\circ} \mathrm{N}$ Test Series

Measurements of wave agitation confirmed results from the numerical modelling with wave agitation being acceptable at berths in the inner part of the harbour.

\section{Overtopping performance}

Overtopping discharges were quantified by collecting the overtopping water in calibrated tanks and measuring the volumes collected in a known time. Three overtopping tanks were placed on the rear side of the breakwater to monitor discharges over the crest.

Two categories of overtopping were investigated:

- Spray - Spray occurs when a wave impacts on to the front of the structure, and the momentum of the water droplets is high enough for them to pass over the structure. The overtopping discharge associated with this type of discharge is very small, generally less than $0.01 \mathrm{l} / \mathrm{s} / \mathrm{m}$, and the volume cannot be measured accurately in the physical model.

- Green water - Green water overtopping occurs when the crest freeboard is small or the wave height is relatively large, and the wave overtops as a continuous body of water.

During testing of armour stability and wave agitation, the most critical sections for overtopping were identified along the breakwater. These were then instrumented to measure wave overtopping before repeating the tests. Location of overtopping collection tanks is indicated in Figure 12. 


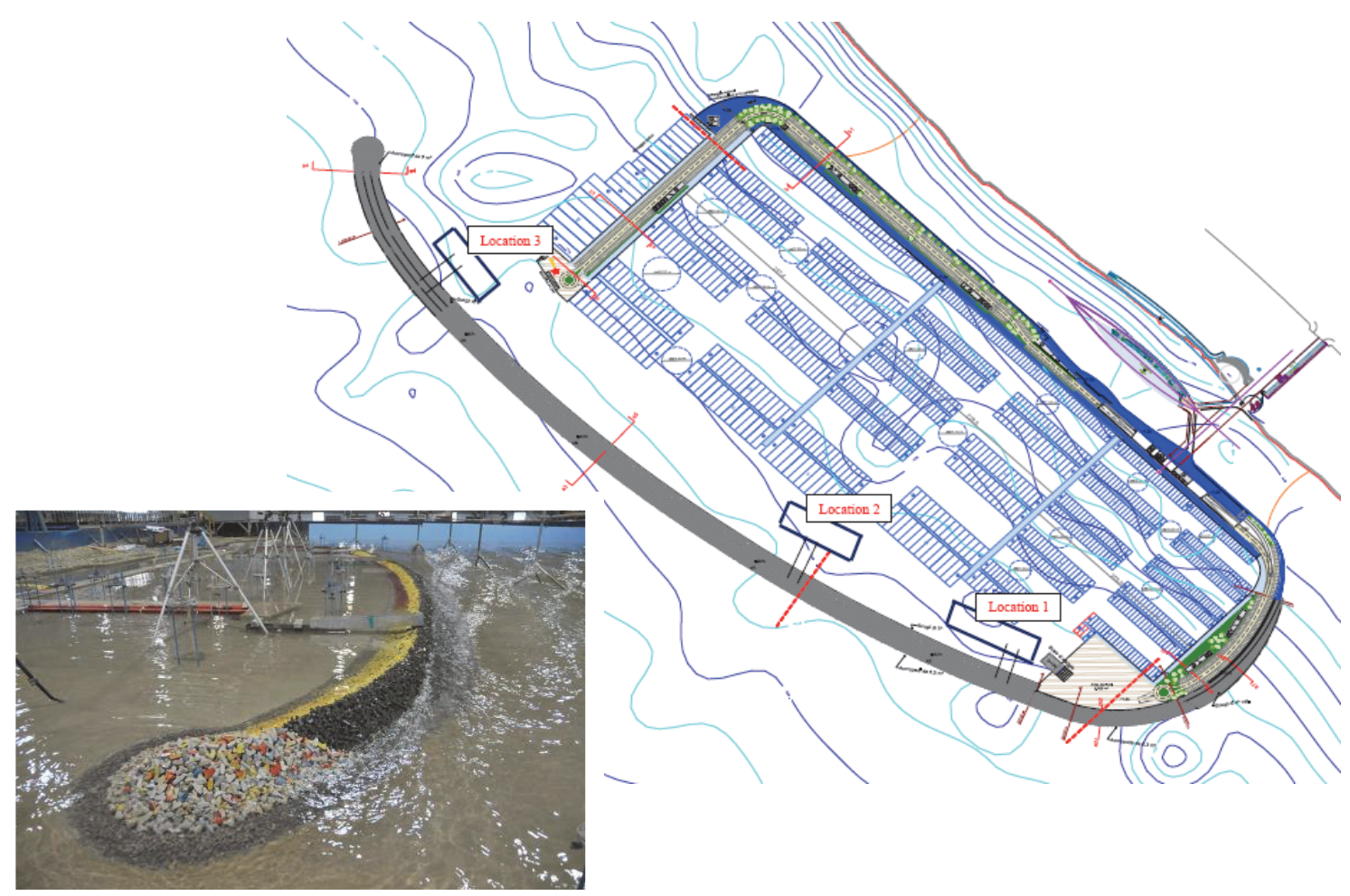

Figure 12. Locations of overtopping tanks for both $210^{\circ} \mathrm{N}$ and $240^{\circ} \mathrm{N}$ Test Series

Overtopping desk calculation and measurements showed that overtopping discharges were compatible with the recommendations given in EurOtop (2007), confirming that the breakwater was designed to an appropriate level for the design conditions.

\section{Circulation}

Dye testing was conducted to ascertain the current flow velocity and direction at site specific locations within and around the marina. Results were obtained by injecting vegetable dye at the mid point in the water column and timed over a 0.5 metre length. Although the length was constant, direction was accounted for by pivoting the fixed length about the start point. Tests were carried out for $1: 1$ year return period for both $210^{\circ} \mathrm{N}$ and $240^{\circ} \mathrm{N}$ wave conditions.

No measurable results were obtained from within the marina. Dye highlighted an almost stagnant water column within the southern end of the marina confirming the need for additional mechanical flushing in this particular area. Dye injected into several locations at the summer berths was observed to have a very slow seiching movement, therefore producing no measurable results. The southern and northern sills act to retain a still channel. At the northern end of the channel the northern sill prevents the currents from accelerating out of the channel and thus significantly reduces the high velocities around the summer berths. Total velocities at the toe of the southern end of the breakwater, recorded for the $210^{\circ} \mathrm{N}$ direction, were observed to be faster than those recorded for the $240^{\circ} \mathrm{N}$ direction and confirmed results obtained with the numerical modelling.

\section{WORK IN PROGRESS}

The construction of the Marina started in September 2010. The main breakwater was constructed from land, by back-dumping core material from trucks. This was trimmed by excavators, and underlayer and armour were placed using excavators and crane. The distance between advancing fronts of core and armour was kept to a minimum to prevent damage to the partially completed structure. Figure 13 shows the construction works in July 2011. 

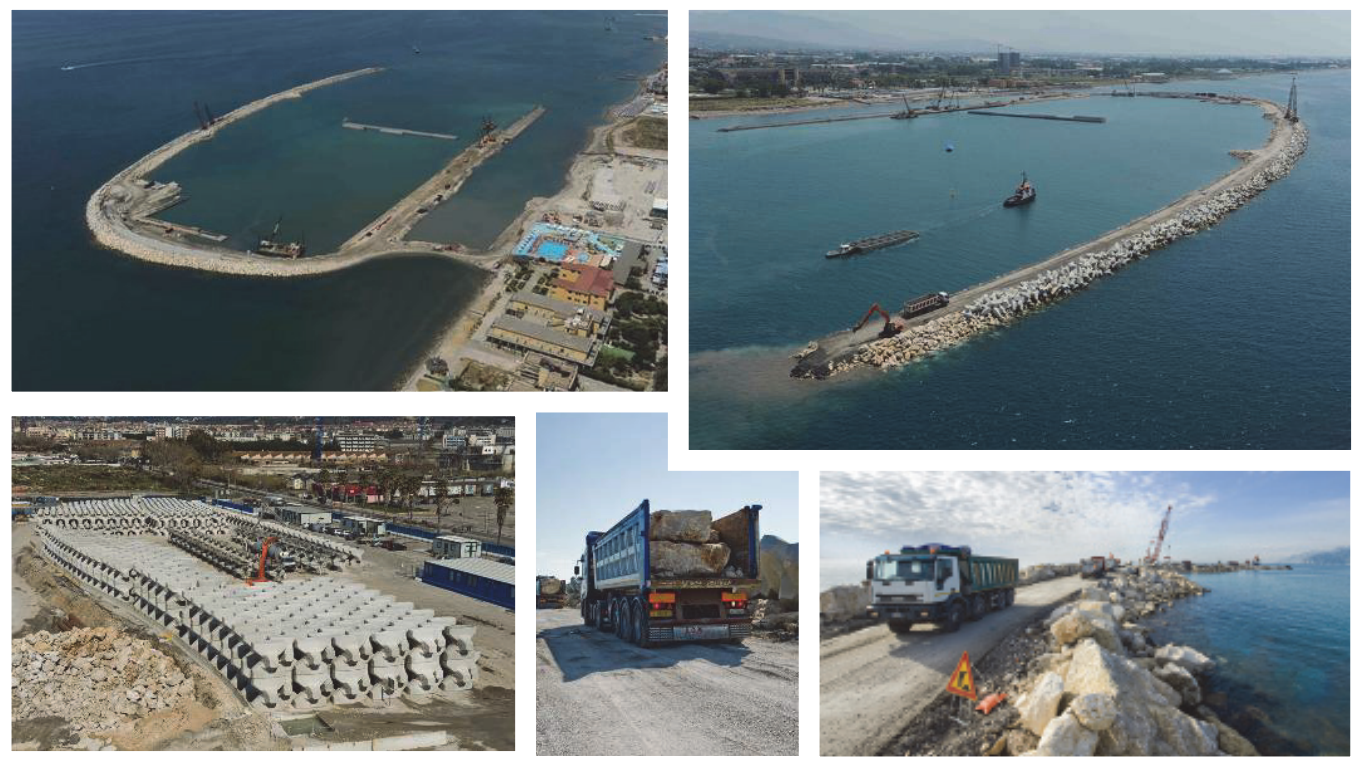

Figure 13. Construction works in July 2011

At the time of writing this paper both breakwaters and parts of the proposed quay walls have been constructed. About 480 berths are ready and available and the Marina is scheduled to be completed by the summer of 2013.

\section{CONCLUSIONS}

Numerical models were used to establish appropriate (offshore and nearshore) forcing conditions and optimise the original design. The hydraulic performance of the proposed development was evaluated in terms of:

- Wave agitation at the marina entrance and berths;

- Potential sedimentation and erosion in the vicinity of the Marina;

- Flushing of the Marina and of the channel between the Marina and the coastline;

- $\quad$ Future long-term beach behaviour adjacent to the Marina.

Based on the analysis of the numerical models results, the following design refinements and recommendations were identified:

- Extension of the main breakwater by $80 \mathrm{~m}$, in order to provide comfortable mooring condition at the 'summer berths';

- Introduction of two sills at either end of the channel between the Marina and the coastline, in order to avoid the risk of sedimentation at both channel entrances;

- Introduction of a discharge of clean water through a pumping system:

○ $1 \mathrm{~m}^{3} / \mathrm{s}$ into the marina basin;

○ $0.1 \mathrm{~m}^{3} / \mathrm{s}$ into the channel between the proposed Marina and the adjacent coastline;

in order to maintain a satisfactory level of water quality.

The breakwater cross sections were then modified to improve stability and reduce overtopping by means of desk studies and the initial design was modified incorporating the refinements and recommendations identified during the numerical model studies. 3D physical model tests were then conducted to verify the hydraulic performances of the proposed design of the Marina.

Measurements of wave agitation and circulation on the 3D physical model, confirmed results obtained with the numerical modelling. 3D physical model tests also confirmed the stability of the breakwater primary armour layer and indicated that overtopping discharges were compatible with the recommendations given in EurOtop (2007), confirming that the breakwater was designed to an appropriate level for the design conditions.

This paper shows the important role of numerical and physical model in the design of a marina and for this particular project the physical model study has confirmed the effectiveness of the proposed works. 


\section{ACKNOWLEDGEMENTS}

This work was funded by Marina D’Arechi S.p.A.. The authors wish to thank Dr Tim Pullen, Dr Jort Wilkens and Tim Chesher (HR Wallingford) for their valuable contribution to the physical and numerical modelling tasks.

\section{REFERENCES}

CLI. 2011 Guidelines for placing models at laboratory. Concrete Layer Innovations.

BSI. 1991 British Standard Code of practice for Maritime structures, Part 7. Guide to the design and construction of breakwaters. BS 6349: Part 7: 1991, British Standards Institution, London.

PIANC. 2008 Protecting water quality in marinas, PIANC Report No 98, Recreational Navigation Commission.

T. Pullen, N.W.H. Allsop, T. Bruce, A. Kortenhaus, H. Schüttrumpf and J.W. Van der Meer. 2007. EurOtop Overtopping Manual, Wave Overtopping of Sea Defences and Related Structures Assessment Manual. 